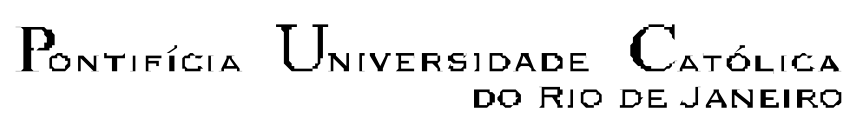

DO RJO DE JANEIRO

Érica Juliana Santos Rocha

\title{
Multimodalidade, Sócio construção do conhecimento e a Sala de aula: \\ Uma associação possível?
}

Dissertação apresentada ao Programa de Pós-graduação em Letras da PUC-Rio como requisito parcial para obtenção do grau de Mestre em Letras.

Orientador: Prof. Barbara Jane Wilcox Hemais 


$$
\begin{aligned}
& \text { Pontificia Universidade Católica } \\
& \text { DO RIO DE JANEIRO }
\end{aligned}
$$

\section{Érica Juliana Santos Rocha}

\section{MULTIMODALIDADE, SÓCIO-CONSTRUÇÃO DO CONHECIMENTO E SALA DE AULA: Uma associação possível?}

Dissertação apresentada como requisito parcial para obtenção do grau de Mestre pelo Programa de PósGraduação em Letras da PUC-Rio. Aprovada pela Comissão Examinadora abaixo assinada.

Prof ${ }^{a}$. Barbara Jane Wilcox Hemais
Orientadora
Departamento de Letras - PUC-Rio

Profa. Inés Kayon de Miller

Departamento de Letras - PUC-Rio

Profa. Isabel Cristina Rangel Moraes Bezerra Universidade do Estado do Rio de Janeiro - UERJ

Prof. Paulo Fernando Carneiro de Andrade Coordenador Setorial do Centro de Teologia e Ciências Humanas - PUC-Rio.

Rio de Janeiro, 31 de outubro de 2008. 
Todos os direitos reservados. É proibida a reprodução total ou parcial do trabalho sem autorização da universidade, da autora e do orientador.

\section{Érica Juliana Santos Rocha}

Graduou-se em Letras - Português/Inglês na FEUC (Fundação Educacional Unificada Campo-Grandense em 2003. Cursos de extensão pela UERJ e UFRJ, além de participar de diversos congressos nestas instituições. Tem atuado como professora de inglês em diversos níveis e instituições desde 2000. Leciona no Colégio Naval - Marinha do Brasil. Membro do Grupo de Estudos em Linguagens e Recursos em Ambientes Pedagógicos (GELAP) - PUC-Rio. Seus interesses são a Multimodalidade, Gêneros Discursivos, Prática Exploratória e Linguística Sócio-Interacional.

Ficha Catalográfica

Rocha, Érica Juliana Santos

Multimodalidade, sócio construção do conhecimento e a sala de aula: uma associação possível? / Érica Juliana Santos Rocha ; orientadora: Barbara Jane Wilcox Hemais. -2008 .

143 f. : il. ; $30 \mathrm{~cm}$

Dissertação (Mestrado em Letras)-Pontifícia Universidade Católica do Rio de Janeiro, Rio de Janeiro, 2008.

Inclui bibliografia

1. Letras - Teses. 2. Textos visuais. 3. Relação ensino-aprendizagem. 4. Construtivismo. 5. Imagens. 6. Multimodalidade. 7. Interação. 8. Sócio-construção de significados. I. Hemais, Barbara Jane Wilcox. II. Pontifícia Universidade Católica do Rio de Janeiro. Departamento de Letras. III. Título. 
Ao meu pai, Alberto, por ter sempre dito: "Oh! Nina, não tenha preguiça para estudar.

$O$ pai quer ver você na universidade, o pai quer ver você doutora."

Para ti, paizinho querido, aqui estou. Doutora? ... Em breve... Este é meu primeiro passo, por você, para você, com todo meu amor 


\section{Agradecimentos}

A Deus, que me deu a força necessária, amando-me e curando as feridas surgidas ao longo do caminho, tornando-me mais confiante, concedendo-me graças diárias para eu chegar até aqui.

À minha mãe, por sua luta para me dar o mundo, por ter aberto o livro da sua vida pra mim, fazendo com que eu fosse capítulo imprescindível da sua história e, finalmente, por ter acreditado sempre no meu sol, mesmo quando as nuvens tentavam encobri-lo. Sem ela, palavra nenhuma poderia ter sido urdida.

Ao meu filho Igor, por ser a razão da minha existência, da minha luta e de todo esforço empregado nesta pesquisa. Toda falta que lhe causei foi pensando, em posteriormente, ser o melhor de mim para você e por você.

À minha melhor amiga e irmã Guiomar, por ter sido tia, dinda e mãe do meu Igor durante o processo desta pesquisa, dedicando-se incansavelmente a ele em todos os momentos em que eu não pude estar presente. A você, todo o meu amor.

Ao Guilherme, pela paciência, preocupação e pela constante motivação, sendo fundamental para que eu recuperasse a auto - estima.

À querida orientadora Barbara, pelo carinho, paciência e delicadeza. Obrigada pela presteza com a qual aceitou orientar-me, acreditando mais em mim que eu mesma. Muito obrigada pela sua exigência, que tanto me fez crescer.

À professora Inés Miller, que significa tanto pra mim, um agradecimento muito especial, por ter, com tão poucas palavras, tocado o meu coração e me convencido a ficar. Esta pesquisa deve muito àquelas suas palavras. Obrigada por ser meu eterno exemplo.

À professora Daisy, por ter sido tão gentil quando eu quis adentrar seu mundo e entendê-lo para fazer este trabalho. Você abriu um espaço seu, permitindo-me "brincar" com ele e agora será eternizada nesta pesquisa.

À professora Shirlane, pela verdadeira parceria, por ter dado conta do recado nos momentos em que eu me ausentei e por toda a cumplicidade, discrição e amizade. 
Ao amigo Amorim, pelos gestos de carinho, pelas palavras sensatas, pelo incentivo, por sempre ter acreditado que eu seria capaz.

Ao coordenador Bartolomeu, que tornou meu ambiente de trabalho propício para que eu fosse professora e pesquisadora ao mesmo tempo e, minha admiração, por ter conduzido a coordenação de forma tão profissional e, ao mesmo tempo, humana.

À professora Maria Helena, por sempre reforçar a minha fé em momentos cruciais. Sua discrição, percepção e delicadeza são admiráveis.

Aos professores Jules e Rafael, por terem sido a minha luz no fim do túnel, quando tudo parecia não ter mais solução. Não existem palavras que possam descrever a minha eterna gratidão por vocês.

Ao Comandante do Colégio Naval, CMG José Luiz, por ter permitido que a pesquisa fosse feita na Instituição.

À Chiquinha, por sua eficiência na secretaria da pós e o tratamento muito gentil sempre dispensado a mim. 


\section{Resumo}

Rocha, Érica Juliana Santos; Hemais, Barbara Jane Wilcox (Orientadora). Multimodalidade, Sócio construção do conhecimento e Sala de Aula: Uma associação possível?. Rio de Janeiro, 2008. 143p. Dissertação de Mestrado - Departamento de Letras, Pontifícia Universidade Católica do Rio de Janeiro.

O objetivo principal deste trabalho de pesquisa é entender o uso de textos visuais na sala de aula e seu impacto na aprendizagem. A pesquisa enfoca o uso de textos visuais para facilitar a aplicação de uma perspectiva pedagógica que objetive a sócio-construção do conhecimento, o sócio-interacionismo, seguindo a concepção de Bakhtin (2000), Freire (1979), Mercer (1994) e Vygotsky (1994). Com essa base teórica, a pesquisa aplica a gramática do desenho visual (Kress \& van Leeuwen, 1996) em um ambiente de sala de aula, ao examinar as interpretações feitas pelos próprios aprendizes em relação às imagens utilizadas pela professora, para que se observa de que forma as observações dos aprendizes evocam as categorias na gramática do desenho visual e, portanto, trazer luz sobre o conhecimento desses aprendizes de como ler imagens. Discute-se as implicações de uma abordagem pedagógica que objetiva construir o letramento visual no ambiente de ensino da língua inglesa.

\section{Palavras-chaves}

Textos visuais; relação ensino-aprendizagem; construtivismo; imagens; multimodalidade; interação; sócio-construção de significados. 


\section{Abstract}

Rocha, Érica Juliana Santos; Hemais, Barbara Jane Wilcox (Orientadora). Multimodality, social construction of meanings and The Classroom: A Possible Association?. Rio de Janeiro, 2008. 143p. Master's Dissertation Departamento de Letras, Pontifícia Universidade Católica do Rio de Janeiro.

The main purpose of this study is to understand the use of visual texts in the classroom and their impact on learning. The research focuses on how the use of visual texts can facilitate the application of a construction of meanings and the socio-interactional perspective on teaching/learning, according to Bakhtin (2000), Freire (1979), Mercer (1994) and Vygotsky (1994). With this theoretical framework, the study applies the grammar of visual design (Kress \& Van Leeuwen, 1996) to a classroom setting by examining the learners' interpretations of the images used by the teacher, to observe to what extent their observations evoke the categories in the grammar of visual design and thus indicate knowledge of how to read images. The study discusses the implications of an approach to teaching and learning that aims at building visual literacy in the setting of English language teaching.

\section{Key words}

Visual texts; learning-teaching process; constructivism; images; multimodality; interaction; negotiation of meaning. 


\section{Sumário}

1. Introdução 14

2. Que relação é essa: ensino-aprendizagem? 19

2.1. Ensino-aprendizagem e as experiências da professorapesquisadora $\quad 20$

2.2. A sócio - construção do conhecimento 23

2.2.1. O construtivismo na concepção piagetiana 24

2.2.2. A sócio - construção na concepção vygotskyana 24

2.3. A inserção da multimodalidade nessa concepção de aprendizagem 26

2.3.1. O texto visual $x$ o texto escrito 28

2.3.2. Como trabalhar a multimodalidade na sala de aula? 29

3. Pressupostos Teóricos $\quad 34$

3.1. Classificações propostas por Kress \& van Leeuwen 35

3.1.1. A narrativa representacional 36

3.1.1.1. Processos de ação 37

3.1.1.2. Processo reacional 38

3.1.1.3. Processo de fala e processo mental 40

3.1.1.4. Processo de conversão $\quad 42$

3.1.1.5. Simbolismo geométrico 43

3.1.1.6. Circunstâncias 43

3.1.2. As representações e as interações 45

3.1.2.1. Ato da imagem e o olhar 45

3.1.2.2. Distância Social 49

3.1.2.3. A perspectiva de uma imagem 52

3.1.3. O significado da composição 56

$\begin{array}{ll}\text { 3.1.3.1. O valor da informação } & 57\end{array}$ 
3.1.3.1.1. Dado e Novo (posicionamento a esquerda e a direita) 57

3.1.3.1.2. Ideal e Real (posicionamento acima ou abaixo) 63

3.1.3.1.3. Centro e Margem 65

$\begin{array}{ll}\text { 3.1.3.2. Saliência } & 67\end{array}$

$\begin{array}{ll}\text { 3.1.3.3. Moldura } & 69\end{array}$

4. Metodologia $\quad 71$

4.1. a pesquisa de diagnóstico 72

4.2. o caráter humanístico da pesquisa $\quad 73$

$\begin{array}{ll}\text { 4.3. o paradigma construtivista } & 74\end{array}$

4.4. a pesquisa de ação 76

4.5. o ambiente pedagógico a ser estudado $\quad 77$

$\begin{array}{ll}\text { 4.6. os participantes da pesquisa } & 79\end{array}$

$\begin{array}{ll}\text { 4.6.1. a professora-pesquisadora } & 79\end{array}$

$\begin{array}{ll}4.6 .2 \text { a professora Daisy } & 80\end{array}$

4.6.3. os alunos 83

4.7 as ferramentas da pesquisa $\quad 85$

4.8 os procedimentos de análise $\quad 85$

5 a análise dos dados $\quad 87$

5.1 a análise dos questionários $\quad 88$

$\begin{array}{ll}5.1 .1 \text { sobre a atividade preferida } & 89\end{array}$

5.1.2 sobre a efetiva participação dos alunos 90

$\begin{array}{ll}5.1 .3 \text { a internalização dos conteúdos } & 91\end{array}$

5.1.4 a preferência pelos recursos utilizados 93

$\begin{array}{ll}5.1 .5 \text { o interesse pelas imagens } & 94\end{array}$

$\begin{array}{ll}5.1 .6 \text { a escolha de um conteúdo } & 97\end{array}$

5.2 a observação das aulas 98

$\begin{array}{lr}5.3 \text { a análise das imagens } & 102\end{array}$

6. Considerações Finais 113

$\begin{array}{ll}\text { 7. Referências bibliográficas } & 116\end{array}$ 
8. Bibliografia

9. Referência Bibliográfica das figuras

10. Anexos

124

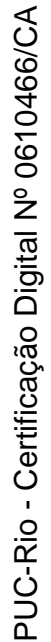




\section{Lista de Figuras}

Figura 1.0 - Impecável- dia dos pais 2007

Figura 2.0 Speech circuit 38

Figura 3.0 Lindinhas sob o Bambu 39

Figura 4.0 Pateta e Mickey recebem um convite para uma festa 40

Figura 5.0 - Menina fala sobre Israel 41

Figura 6.0 Ciclo da água $\quad 42$

Figura 7.0 setas ampliadas $\quad 43$

$\begin{array}{ll}\text { Figura } 8.0 \text { setas curvas } & 43\end{array}$

Figura 9.0 O Barco em Giverny $\quad 44$

$\begin{array}{ll}\text { Figura } 10 \text { Pipa Vestida } & 47\end{array}$

$\begin{array}{ll}\text { Figura } 11 \text { Menina entrevistadora } & 48\end{array}$

Figura 12 Conversa na biblioteca 49

Figura 13 Olhar sedutor $\quad 51$

Figura 14 Orquestra Filarmônica de São Caetano do Sul 52

Figura 15 Série Mestre, Sebastião Salgado $\quad 54$

Figura 16 Prédio Russo $\quad 55$

Figura 17 A noite cai sobre a Europa e a África 56

Figura 18 A Criação do Cebolinha $\quad 59$

Figura 19 Atrevida 60

Figura 20 O uso do will 62

Figura 21 Propaganda de cosméticos $\quad 64$

Figura 22 Cores de sombras $\quad 66$

Figura 23 Dado / Mediador / Novo $\quad 67$

Figura 24 Lábios Provocantes 68

Figura 25 Ponte sobre o rio Daiya, Japão 69

Figura 26 Enfoques diferentes $\quad 70$ 
Que a aprendizagem seja uma extensão progressiva do corpo, que vai crescendo, não apenas em seu poder de compreender $e$ conviver com a natureza, mas em sua capacidade para sentir o prazer, o prazer da contemplação... Afinal, nem é para isto que vivemos, o puro prazer de estarmos vivos?

Rubem Alves, Escola: Fragmento do Futuro 